\title{
Anatomical Differences in the Abdominal Wall Between Spe- cies with Implications for the Transversus Abdominis Plane Block
}

\author{
Jevan Cevik ${ }^{1,2}$, David J Hunter-Smith ${ }^{1,2}$, Warren M. Rozen ${ }^{1,2}$
}

1 Department of Plastic and Reconstructive Surgery, Peninsula Health, Frankston, Victoria, Australia

2 Peninsula Clinical School, Central Clinical School, Faculty of Medicine, Monash University, Frankston, Victoria, Australia

* Correspondence: warrenrozen@hotmail.com

Simple Summary: Animal models are being increasingly used in medicine for simulation based teaching of many procedures including the transversus abdominis plane block. This procedure involves the injection of local anaesthetic into the abdominal wall. Given this, an increased understanding of the anatomy of the abdominal wall across species is required to effectively utilize animal models in this manner. This review aims to compare the abdominal wall anatomy across species and discuss any implications for the transversus abdominis plane block. Differences in the musculature, vasculature and innervation of the abdominal wall are discussed. It was determined that for medical training purposes, mammals are recommended given the similarities in abdominal wall anatomy. More specifically, for the transversus abdominis plane block, the pig is recommended as the most suitable model.

\begin{abstract}
With the increased use of simulation based training using animal models for the education of surgical and anaesthetic techniques, an increased understanding of the anatomy of such models and how they compare to humans is required. The transversus abdominis plane block is a regional anaesthetic technique that requires an understanding of the abdominal wall anatomy along with proficient ultrasound use. The current review aims to compare the anatomy of the abdominal wall across species, particularly focussing on the pertinent differences within the class of mammals, and secondarily, it aims to address the implications of these differences for simulation based training of the transversus abdominis plane block. To achieve this, the PubMed, Web of Science and Google Scholar databases were searched for relevant literature. The mammalian abdominal wall differs in its musculature, vasculature or innervation from that of amphibians, birds or reptiles, however, among species of mammals, the structure of the abdominal wall follows a similar framework. Particular differences among mammals include the additional muscular layer of the panniculus carnosus found in most mammals other than humans, the variable arterial origins and dominant vascular supply of the abdominal wall and the number of thoracolumbar nerves innervating the abdominal wall. When using animal models for simulation based training, the pig is recommended for the transversus abdominis plane block given its closely homologous abdominal wall structure, availability and larger comparative size.
\end{abstract}

Keywords: Abdominal wall; Transversus abdominis plane block; Comparative anatomy; Animal models

\section{Background}

The abdominal wall is an anatomical site that is frequently involved in operations across multiple surgical specialties. During procedures involving the abdominal wall, regional anaesthesia can be used to provide analgesia to the involved surgical site. One particular technique involving the abdominal wall is the transversus abdominis plane (TAP) block which involves an injection of local anaesthetic into the TAP between the transversus abdominis and internal oblique muscles [1]. The use of ultrasound has become 
increasingly common to locate the intended fascial plane to be injected, however, developing the skill-set required for its use can be challenging and trainees may make more errors putting patients at risk [2-5]. The use of simulation based training and animal models can help new trainees develop skills in a safe environment and improve their confidence in the procedure [4,6-8]. Given the increased use of simulation based training in teaching regional anaesthetic techniques such as the TAP block, an improved understanding of the anatomical differences between animal species and humans is warranted to both, select the most appropriate model and to guide their use for education.

Hence, this review aims to compare the anatomy of the anterolateral abdominal wall across species, with a particular focus on anatomical differences in the musculature, vasculature and innervation of the abdominal wall among mammals. Secondarily, this review aims to identify the implications of these differences for the use of animal models in simulation based medical education.

\section{Methods}

The information used to write this article came from searches of the PubMed, Web of Science and Google Scholar databases. Search criteria keywords contained within the title or abstract of the article included variations of the terms ('Anatomy' OR 'Anatomical') AND ('Abdominal wall') AND ('Musculature' OR ‘Muscle' OR ‘Vasculature' OR ‘Blood supply' OR 'Artery' OR 'Arterial' OR 'Arteries' OR 'Vessel' OR 'Innervation' OR 'Nerve') AND ('Animal') AND ('Mammal' OR ‘Reptile' OR ‘Bird' OR 'Amphibian' OR 'Dog' OR 'Cat' OR 'Pig' OR 'Rat' OR 'Rabbit' OR 'Guinea Pig' OR 'Horse' OR 'Monkey' OR 'Primate'). Furthermore, additional subsequent searches were performed in the same databases in attempts to find more precise information. For example, one search contained the keywords: ('Deep Inferior Epigastric Artery' OR ‘Inferior Epigastric Artery' OR ‘Epigastric Artery') AND ('Pig'). Additionally, relevant citations from previous studies were reviewed for eligibility. Abstracts and titles of relevant articles obtained from the search or from key citations were reviewed for relevance and have been cited where included. Subsequently, the full texts of the selected literature was reviewed. Studies were included if they reported information pertaining to the musculature, vasculature or innervation of the anterolateral abdominal wall across species. Studies that did not report on these outcomes or those in languages other than English, where a translated article was not obtainable, were excluded. Ultimately, the information surrounding the anatomy of the abdominal wall across species was synthesised and presented in the current review.

\section{Comparison of the Tetrapods}

The tetrapods comprise four-limbed animals and is the superclass containing the four subclasses of mammals, amphibians, birds and reptiles [9]. As these animals further evolved, differentiating themselves from fish and the other animal classes, the anatomy of their abdominal walls began to follow a similar framework [10]. Such that, within mammals, the general structure of the abdominal wall is largely conserved [11].

\subsection{MUSCULATURE}

The muscles of the abdominal wall act to compress the abdominal viscera and increase abdominal pressure, assist with expiration and in combination produce flexion of the trunk. The mammalian abdominal wall typically consists of four muscular layers laterally, namely, the panniculus carnosus (absent in humans), the external oblique, the internal oblique and the transversus abdominis muscle. In the midline, the rectus abdominis muscle is also present. This structure, is similarly seen in birds, where, except for the panniculus carnosus, the same muscular layer exists [12].

Variations to this pattern are observed among reptiles. In the abdominal wall of certain reptiles, muscles not present in mammals can be found such as the rectus abdominis lateralis muscle found in some species of lizard and the ischiotruncus and truncocaudalis muscle found in species of alligators and crocodiles [13-15]. In other 
species of lizards, the internal oblique muscle is absent [16]. Furthermore, in some species of turtles, the abdominal wall is comprised of only two muscular layers [17].

Amphibians exhibit the most variable and dissimilar abdominal wall musculature to the other tetrapods. The muscular layers of the amphibian abdominal wall are variable consisting anywhere between two to four muscles. In certain species, the muscles of the rectus abdominis or the external oblique can be split into a deep (e.g. M. obliquus externus profundus) and a superficial layer (e.g. M. obliquus externus superficialis) [10,18-20].

Across animal classes, the abdominal wall musculature is variable. Both the number of muscular layers and the muscles present are heterogenous. Yet, the general function of the abdominal wall muscles is conserved. Mammals and birds show markedly similarity whereas certain species of amphibians and reptiles can be quite dissimilar.

\subsection{VASCULATURE}

Like that of the abdominal wall musculature, the blood supply to the abdominal wall is relatively conserved in mammals. The vasculature arises from three main origins: 1 ) the internal thoracic artery superiorly, 2) the intercostal and lumbar arteries laterally and 3) the iliac or femoral arteries inferiorly [21,22].

These origins give rise to certain key arteries [21-23], including:

- The superficial superior epigastric artery (SSEA) and the superficial inferior epigastric artery (SIEA)

- The deep inferior epigastric artery (DIEA) and the deep superior epigastric artery (DSEA)

- $\quad$ The deep circumflex iliac artery (DCIA)

- The musculophrenic arteries

- The intercostal, subcostal and lumbar arteries

Within the class of mammals, specific variations to this general framework are apparent and will be discussed later.

Despite significant differences in the morphology of their heart and the presence of two aortas, the vascular supply of the abdominal wall in species of amphibians such as the toad and frog resembles that of mammals [21,24]. As in mammals, the arteries travelling to the abdominal wall arise from quite similar origins. Arteries that are homologous to the internal thoracic artery, DIEA and DCIA can all be seen in the toad and frog $[21,24,25]$. Furthermore, an artery that has a similar vascular supply to the SSEA in humans can be found in the frog, where it is named the cutaneous artery and originates as a branch off a common trunk off the respective right and left aortas [24,25]. Moreover, while the terminology is different, a similar vascular distribution pattern to the abdominal wall is seen in species of salamanders [26].

In contrast, despite the similarities in the musculature of their abdominal wall, the vasculature of the avian abdominal wall is quite dissimilar to that of humans. The vascular supply to the avian abdominal wall is almost entirely supplied from a single origin superiorly off the subclavian artery [12,21,27]. This contrasts to humans where the dominant vascular supply consists of the DIEA which extends from an inferior origin off the external iliac artery [23]. In fact, the inferior vessels found in humans of the DIEA and the DCIA appear to have no homologous counterpart in birds $[12,21,27]$. Birds exhibit an internal thoracic artery like that of mammals, however, unlike mammals, it arises from a common trunk off the subclavian artery known as the pectoral trunk, rather than as an individual branch off the subclavian artery [12,21,27]. Furthermore, in the bird, the internal thoracic artery does not branch into the DSEA and provides minimal vascular supply to the abdominal wall $[12,21,27]$. Instead, the other branches off the pectoral trunk travel to and supply the majority of the abdominal wall. In the bird these arteries are known as the external thoracic artery, the cutaneous thoracoabdominal artery and the caudal pectoral artery $[12,27]$. When compared to humans, the path of these arteries 
reflects the path of the lateral thoracic artery found in humans $[12,21,27]$. The greater reliance on these lateral vessels may reflect the greater importance placed on the pectoral muscles of the bird due to their use in flight.

The vascular supply to the abdominal wall in reptiles certainly appears different, however, one can see similarities that reflect the system seen in mammals. In species of turtles, an artery called the epigastric artery resembles the DCIA that is found in humans, however, in the turtle it arises from the abdominal aorta as opposed to the external iliac in humans[28,29]. This artery travels cranially to anastomose with an artery called the marginocostal artery that travels laterally along the turtle's shell $[28,29]$. The marginocostal artery arises from the axillary artery and, although relatively larger, it appears similar to the lateral pectoral artery found in humans $[28,29]$. In other species of reptiles, such as lizards, arteries homologous to the DIEA and the DSEA can be seen [30].

\subsection{NERVES}

The innervation of the abdominal wall across the class of tetrapods largely involves the same group of nerves, the thoracic, lumbar and occasionally sacral spinal nerves. Yet, because the number of vertebrae shows high variability across species, the specific nerves that will travel and innervate the abdominal wall varies. In mammals, the abdominal wall is typically innervated by the lower thoracic nerves and the upper lumbar nerves, although in some species this can extend to include the sacral nerves as well [31-33]. In birds, the number of nerves innervating the musculature and overlying skin of the abdominal wall is reduced. For instance, chickens exhibit only seven thoracic spinal nerves and a smaller subset of these nerves along with the upper lumbar nerves innervate the anterolateral abdominal wall [12,27]. Similarly, in certain species of frogs, 10 pairs of spinal nerves are present and only four innervate the abdominal musculature and overlying cutaneous tissue [24,26]. However, in other species of amphibians such as salamanders or in species of reptiles with longer bodies, a larger number of thoracic and lumbar vertebrae are present and therefore the number of spinal nerves innervating the abdominal wall increases [26,34,35].

It appears that the innervation of the abdominal wall among species of tetrapods has a consistent origin from the spinal nerves exiting the spinal cord, yet differences arise in the number of nerves travelling to the abdominal wall and this is largely proportional to the number of thoracic and lumbar vertebrae.

\section{Further Comparison of Mammals}

As aforementioned, the structure of the abdominal wall among mammals is strongly conserved following a common blueprint, however, certain species exhibit deviations from this common framework. In the human, the abdominal wall consists of eight layers, from superficial to deep: skin, superficial fascia (divided into Camper's \& Scarpa's fascia below the umbilicus), external oblique, internal oblique, transversus abdominis, transversalis fascia, pre-peritoneal fat and lastly the parietal peritoneum [36]. The blood supply originates from three major sources, the internal thoracic arteries superiorly, the external iliac arteries inferiorly and the intercostal, subcostal and lumbar arteries laterally [23]. Lastly, the musculature and overlying skin and soft tissue receives innervation from the thoracolumbar nerves (typically T6 to L1 in humans) [33].

\subsection{MUSCULATURE}

Compared to humans, mammals exhibit a relatively homologous muscular structure of the abdominal wall with certain differences. One of the largest differences in the abdominal wall between humans and other mammals is the presence of a panniculus carnosus in most mammals including rats, rabbits, cats, dogs, pigs, horses, monkeys and even whales [21,37-39]. This structure is a thin, superficial muscular layer that lies in close proximity to the skin just deep to the subcutaneous fat and covers most of the abdomen and thorax [37]. This muscle allows mammals to independently move the skin over which it is present. It is thought to play a role in thermogenesis where it allows for shivering and 
heat production in mammals [37,39]. It is largely absent in humans, however, the platysma muscle of the neck is thought to be a vestigial remnant of the panniculus carnosus [37].

In contrast, the pyramidalis muscle, that arises from the pubic symphysis and inserts into the linea alba in humans, is notably absent in most non-primate mammals $[11,38,40,41]$. This muscle is thought to be vestigial in humans, where it is absent in between 10 to $20 \%$ of the population [42-44]. Comparatively, the pyramidalis muscle has been thought to be associated with muscles in the pouch of marsupials such as the kangaroo [45].

Otherwise, the muscular layers of the abdominal wall among mammals include the same four muscles: the rectus abdominis muscle in the midline and the external oblique, the internal oblique and the transversus abdominis muscles anterolaterally. Yet, minor variations in the attachment points for these abdominal muscles in mammals are observed. These differences in origin and insertion of the abdominal muscles are largely due to the different skeletal structures in humans compared to other mammals. For instance, dogs, cats and rats exhibit a $13^{\text {th }}$ rib that is absent in humans which serves as an attachment site for the abdominal muscles [11,46-49]. This is again seen in pigs with 15 to 17 ribs and horses who have 18 ribs [31,38].

Furthermore, the superior/cranial extent of the rectus abdominis muscle is heterogenous among species of mammals. The rectus abdominis muscle of the pig inserts at a location resembling that of the human [21]. However, in many other mammals, the rectus abdominis inserts relatively higher onto the chest wall than it does in humans $[21,50]$. This has implications for the blood supply to this muscle where the superior portion will receive additional branches from the internal thoracic artery in animals with a more significant cranial extent of the rectus abdominis muscle [21].

Variations across species are also observed in relation to the external oblique muscle. In humans, the inferior extent of the external oblique muscle becomes aponeurotic to insert into the pubic crest and pubic tubercle. In rats, the inferior insertion of the external oblique remains muscular to a greater extent than what is observed in humans [51]. Furthermore, among species of bats, the external oblique muscle is much less significant and the internal oblique and transversus abdominis constitute the majority of the abdominal wall [52]. Additionally, in primates, the costal origin of the external oblique originates higher from the $3^{\text {rd }}$ or $4^{\text {th }}$ rib, whereas it most commonly originates from the $5^{\text {th }}$ rib or below in humans [53].

Moreover, differences in the location of the aponeurotic layers that form the rectus sheath have been observed in primates when compared to humans. In humans, the rectus sheath is formed by the aponeuroses of the lateral abdominal wall muscles. Above the arcuate line, the external oblique aponeurosis passes anterior to the rectus abdominis and the transversus abdominis aponeurosis passes posteriorly, while the internal oblique aponeurosis splits to contribute to both the anterior and posterior layers. Below the arcuate line, the aponeuroses all pass anterior to the rectus abdominis. In certain species of monkeys, the aponeurosis of the internal oblique muscle has been seen to pass either completely anterior or posterior to the rectus abdominis muscle for its entire length, contrasting to the situation seen in humans [53].

Overall, the abdominal muscles among mammals are largely similar, however, certain differences are apparent that are important to acknowledge.

\subsection{VASCULATURE}

The blood supply of the abdominal wall exhibits various differences across species of mammals. One of the most significant points of variation among mammals is the cutaneous blood supply of their skin. The skin of mammals has been identified to be fixed (such as that of the pig and, to a degree, humans) or mobile (such as that of the rabbit) [21]. Most mammals have areas of their skin that are fixed (for example the palm of the hand or sole of the foot in humans) and areas that are mobile (for example the dorsum of the hand). Interestingly, the degree of skin fixation has been associated with variations in the cutaneous vasculature among mammals, including the vasculature of the abdominal wall $[21,54]$. The skin of animals with relatively fixed skin (such as the pig) consists of 
vascular supply by many small musculocutaneous perforators whereas in those with mobile skin (such as rats or rabbits), the cutaneous vasculature consisted of fewer yet larger vessels that course subcutaenously $[21,54,55]$. This has been thought to have implications for raising flaps in areas with overlying fixed skin where the blood supply may be tenuous if the muscle is not taken with the flap [21].

Further differences arise when considering the dominant vascular supply to the abdominal wall among species. The human blood supply is similar to that of the monkey, cat and dog [21]. This similarity refers to the larger reliance on the DIEA than the DSEA[21]. In other mammals, such as the rabbit, pig, rat and guinea pig the DSEA predominates [21,56-58]. This is supported by the fact that in pigs, rats and rabbits the DSEA has been shown to provide the vast majority of the musculocutaneous perforators to the abdominal wall, contrasting to the DIEA in humans [57,58].

Additionally, variations in the origins of the arteries supplying the abdominal wall are observed across species (Table 1). For instance, in dogs and cats, the DCIA originates as a primary branch off the abdominal aorta and in pigs it originates from the common iliac artery $[47,57,59]$. This differs from humans where it branches off the external iliac artery. Furthermore, in pigs, dogs and rabbits the DIEA arises from a common trunk (pudendoepigastric trunk) which itself branches variably off the external iliac, femoral or deep femoral arteries $[11,60]$. This contrasts to humans where the DIEA originates as an individual branch off the external iliac artery [23]. Additionally, the SIEA arises as a branch off the external pudendal artery in dogs, whereas in humans it is a unique branch off the common femoral artery [11,47].

Furthermore, many mammals (pig, cat, dog, rat and rabbit) exhibit an artery that is absent in humans, namely, the caudal abdominal artery (along with its cranial counterpart) [11,21,47]. This artery arises from the external iliac artery in dogs and cats and the femoral artery in other mammals and travels to supply the caudal abdominal wall $[11,21,47,61]$.

In summary, the vascular supply of the abdominal wall among mammals displays variations on a similar common framework. Notable differences include variations in the cutaneous supply to the overlying abdominal skin, differences in the relative contribution of each vessel to the abdominal wall, deviations in the origins of homologous vessels and the presence of additional arteries in some species.

Table 1. Origin of abdominal vasculature across species $[11,21,23,47,54,60-67]$

\begin{tabular}{|c|c|c|c|c|c|}
\hline Vessel & Human & Dog & Rat & Pig & Rabbit \\
\hline Caudal abdominal artery & - & $\begin{array}{l}\text { External iliac } \\
\text { artery }\end{array}$ & Femoral artery & $\begin{array}{l}\text { Femoral Ar- } \\
\text { tery }\end{array}$ & Femoral artery \\
\hline $\begin{array}{c}\text { Deep superior epigastric ar- } \\
\text { tery }\end{array}$ & $\begin{array}{l}\text { Internal tho- } \\
\text { racic artery }\end{array}$ & $\begin{array}{l}\text { Internal tho- } \\
\text { racic artery }\end{array}$ & $\begin{array}{l}\text { Internal tho- } \\
\text { racic artery }\end{array}$ & $\begin{array}{l}\text { Internal tho- } \\
\text { racic artery }\end{array}$ & $\begin{array}{l}\text { Internal tho- } \\
\text { racic artery }\end{array}$ \\
\hline $\begin{array}{c}\text { Deep inferior epigastric ar- } \\
\text { tery }\end{array}$ & $\begin{array}{l}\text { External iliac } \\
\text { artery }\end{array}$ & $\begin{array}{l}\text { Pudendoepi- } \\
\text { gastric trunk }\end{array}$ & $\begin{array}{l}\text { External Iliac } \\
\text { artery }\end{array}$ & $\begin{array}{l}\text { Pudendoepi- } \\
\text { gastric trunk }\end{array}$ & $\begin{array}{l}\text { Pudendoepi- } \\
\text { gastric trunk }\end{array}$ \\
\hline $\begin{array}{l}\text { Superficial inferior epigas- } \\
\text { tric artery }\end{array}$ & $\begin{array}{l}\text { Common fem- } \\
\text { oral artery }\end{array}$ & $\begin{array}{l}\text { External pu- } \\
\text { dendal artery }\end{array}$ & Femoral artery & $\begin{array}{l}\text { Deep inferior } \\
\text { epigastric ar- } \\
\text { tery }\end{array}$ & Femoral artery \\
\hline Deep circumflex iliac artery & $\begin{array}{l}\text { External iliac } \\
\text { artery }\end{array}$ & $\begin{array}{l}\text { Abdominal } \\
\text { aorta }\end{array}$ & $\begin{array}{l}\text { External iliac } \\
\text { artery }\end{array}$ & $\begin{array}{l}\text { Common iliac } \\
\text { artery }\end{array}$ & $\begin{array}{l}\text { Common iliac } \\
\text { artery }\end{array}$ \\
\hline
\end{tabular}




\subsection{NERVES}

The innervation of the abdominal wall in mammals follows a similar pattern among species [68]. That is, it receives innervation laterally from the thoracic (as a continuation of the intercostal and subcostal nerves) and lumbar spinal nerves. Moreover, as in humans, the anterior branches of these nerves travel in a transverse direction within the transversus abdominis plane (TAP) between the transversus abdominis and internal oblique muscles.

However, among species, the spinal nerves that travel to and innervate the abdomen vary. In humans, the abdominal wall is typically supplied by spinal nerves T6 to L1 [33], this differs in other mammals. For instance, in the rat, the abdominal wall is supplied by nerve roots T5 to S1 [32]. Similarly, in cats, the abdominal wall receives innervation from spinal nerves T6 to L5 $[69,70]$. Furthermore, given the variable number of thoracic and lumbar vertebrae among mammals, the number of spinal nerves innervating the abdomen is also variable. The abdominal wall in pigs receives innervation from spinal nerves approximately originating from $\mathrm{T} 6$ to $\mathrm{L} 3$ and that of horses receives innervation between T5 to L2 [31,38]. However, given the increased number of thoracic vertebrae among pigs and horses (15 to 17 , and 18 respectively), this comprises many more nerves than that is observed in humans [31,38].

The canine abdominal wall receives innervation from spinal nerves T7 to L3 and, as previously mentioned, dogs have a $13^{\text {th }}$ thoracic vertebrae (and subsequent rib and spinal nerve) that is absent in humans [46,47,71-73]. Interestingly, in dogs, the umbilicus is innervated by $\mathrm{T} 10$ as it does in humans [47,71]. Additionally, there is considerable variation in the course of the canine upper thoracic nerves from T7 to T9 and their presence in the TAP. Often, only the spinal nerves from T10 to L2 are found within the TAP of dogs [72]. Similarly, in primates, the upper T8 and T9 are occasionally absent from the TAP overlying the transversus abdominis [53].

In the rat, a nerve that has no true analogue in humans can be found called the caudal epigastric nerve [74]. This nerve originates as a branch of the saphenous nerve and courses with the superficial inferior epigastric vessels to innervate the overlying skin of the caudal abdomen in the rat [74]. Interestingly, this nerve is also absent in other mammals including the dog, pig, monkey and rabbit $[11,68,74]$.

Overall, abdominal wall innervation among mammals is similar, the main differences arise when considering the number of nerves innervating the abdomen across species.

\section{Implications for the Transversus Abdominis Plane Block}

Given the increased use and benefit of simulation training using animal models to practice ultrasound guided regional anaesthetic techniques, an increased understanding of the anatomical differences and similarities in the abdominal wall between humans and other animals is required [4,6-8].

As one would expect, the abdominal wall of mammals best reflects the system seen in humans. Amphibians, birds and reptiles all show marked dissimilarities in the musculature, vasculature or innervation of their abdominal wall. Hence, when selecting an appropriate animal model for training purposes, a mammalian model would offer the most benefit comparatively.

Within the class of mammals, species differ in their relative utility as a model for simulation based training. Monkeys exhibit the most similar constitution of the abdominal wall to humans, however, the limited availability, cost and ethical considerations may make this animal an ineffective training model [75]. Similar reasons may limit the use of canines [75]. Smaller mammals, such as the rat or rabbit, are more readily available and cheaper, however, given the large difference in size between these animals and the average human, the translation of skills practiced on these models to humans is limited. The pig is an animal model that shows quite similar abdominal wall structure to humans and offers reasonable availability, moreover, given its larger size, it is better suited as a training model to simulate procedures performed in humans [76]. 
There are certain anatomical differences in the abdominal wall between humans and other mammals that educators and trainees should be aware of. Firstly, the additional muscular layer of the panniculus carnosus that is found in mammals, but is absent in humans, is important to note. This has implications when evaluating ultrasound images on mammalian animal models and one must differentiate between this layer and the layers of the anterolateral abdominal wall.

Furthermore, across species the number of nerves innervating the abdominal wall differs and their relative target location on the abdominal wall is dissimilar. This has implications on the utility of using animal models to teach greater specifics of the TAP block. In humans, there are numerous approaches used to administer the anaesthetic used in the TAP block. These include the subcostal, lateral and posterior approaches among others [1]. Depending on the specific approach utilised, different target nerves and therefore different target areas of the abdominal wall are anaesthetised [1]. However, given the disparity in abdominal wall innervation between humans and other mammals, the ability to teach trainees specifics regarding needle placement for targeted anaesthetic of specific target nerves in humans is limited.

Additionally, the upper thoracic nerves (T7-T9 in dogs, T8 and T9 in monkeys) supplying the abdominal wall in the TAP has been shown to be sporadically absent in certain mammalian species. This may suggest that the nerves within the TAP among mammals, including humans, is variable. Hence, this has implications when planning an anaesthetic of the superior aspect of the abdomen where a TAP block may not be sufficient to anaesthetise these nerves.

\section{Conclusion}

In this review the anatomical differences in musculature, vasculature and innervation of the abdominal wall across species has been described. Overall, the abdominal wall differs between the various classes of tetrapods but is highly conserved within the class of mammals. Despite marked similarities among mammals, certain anatomical differences exist. Having a greater understanding of the anatomy of the abdominal wall across species is important to acknowledge the applicability and utility of animal models for simulation based teaching of procedures such as the transversus abdominis plane block.

Author Contributions: Conceptualization, W.R.; methodology, J.C. DHS and W.R.; investigation, J.C.; data curation, J.C.; writing - original draft preparation, J.C.; writing-review and editing, J.C., DHS and W.R.; visualization, J.C..; supervision, DHS and W.R.; project administration, DHS and W.R.; All authors have read and agreed to the published version of the manuscript.

Funding: This research received no external funding

Institutional Review Board Statement: Not applicable

Informed Consent Statement: Not applicable

Conflicts of Interest: The authors declare no conflict of interest.

\section{References}

1. Tsai, H.C.; Yoshida, T.; Chuang, T.Y.; Yang, S.F.; Chang, C.C.; Yao, H.Y.; Tai, Y.T.; Lin, J.A.; Chen, K.Y. Transversus Abdominis Plane Block: An Updated Review of Anatomy and Techniques. Biomed Res Int 2017, 2017, 8284363, doi:10.1155/2017/8284363.

2. Barrington, M.J.; Wong, D.M.; Slater, B.; Ivanusic, J.J.; Ovens, M. Ultrasound-Guided Regional Anesthesia: How Much Practice Do Novices Require Before Achieving Competency in Ultrasound Needle Visualization Using a Cadaver Model. Regional Anesthesia Eamp; Pain Medicine 2012, 37, 334-339, doi:10.1097/AAP.0b013e3182475fba.

3. Munirama, S.; Zealley, K.; Schwab, A.; Columb, M.; Corner, G.A.; Eisma, R.; McLeod, G.A. Trainee anaesthetist diagnosis of intraneural injection\&\#x2014; a study comparing B-mode ultrasound with the fusion of B-mode and elastography in the soft embalmed Thiel cadaver model. British Journal of Anaesthesia 2016, 117, 792-800, doi:10.1093/bja/aew337. 
4. Kim, T.E.; Tsui, B.C.H. Simulation-based ultrasound-guided regional anesthesia curriculum for anesthesiology residents. Korean J Anesthesiol 2019, 72, 13-23, doi:10.4097/kja.d.18.00317.

5. de Oliveira Filho, G.R.; Helayel, P.E.; da Conceição, D.B.; Garzel, I.S.; Pavei, P.; Ceccon, M.S. Learning curves and mathematical models for interventional ultrasound basic skills. Anesth Analg 2008, 106, 568-573, table of contents, doi:10.1213/ane.0b013e3181605412.

6. Park, S.J.; Kim, H.J.; Yang, H.-M.; Yoon, K.B.; Lee, K.-Y.; Ha, T.; Jang, H.; Kim, S.H. Impact of simulation-based anesthesiology training using an anesthetized porcine model for ultrasound-guided transversus abdominis plane block. $J$ Int Med Res 2020, 48, 300060519896909-300060519896909, doi:10.1177/0300060519896909.

7. Chen, X.X.; Trivedi, V.; AlSaflan, A.A.; Todd, S.C.; Tricco, A.C.; McCartney, C.J.L.; Boet, S. Ultrasound-Guided Regional Anesthesia Simulation Training: A Systematic Review. Reg Anesth Pain Med 2017, 42, 741-750, doi:10.1097/aap.0000000000000639.

8. Niazi, A.U.; Haldipur, N.; Prasad, A.G.; Chan, V.W. Ultrasound-guided regional anesthesia performance in the early learning period: effect of simulation training. Reg Anesth Pain Med 2012, 37, 51-54, doi:10.1097/AAP.0b013e31823dc340.

9. Hildebrand, M. Analysis of vertebrate structure; Wiley: New York, 1982.

10. Hall, M.I.; Rodriguez-Sosa, J.R.; Plochocki, J.H. Reorganization of mammalian body wall patterning with cloacal septation. Scientific Reports 2017, 7, 9182, doi:10.1038/s41598-017-09359-y.

11. Singh, B.; Dyce, K.M. Dyce, Sack, and Wensing's textbook of veterinary anatomy; 2018.

12. König, E.; Korbel, R.; Liebich, H. Avian Anatomy: Textbook and Colour Atlas; 5m publishing: 2016.

13. Bhullar, B.A. A reevaluation of the unusual abdominal musculature of squamate reptiles (Reptilia: Squamata). Anat Rec (Hoboken) 2009, 292, 1154-1161, doi:10.1002/ar.20955.

14. Fechner, R.; Schwarz-Wings, D. The muscles of the infrapubic abdominal wall of a 6-month-old Crocodylus niloticus (Reptilia: Crocodylia). Anat Histol Embryol 2013, 42, 175-182, doi:10.1111/ahe.12000.

15. Rose, K.A.R.; Tickle, P.G.; Elsey, R.M.; Sellers, W.I.; Crossley, D.A., 2nd; Codd, J.R. Scaling of axial muscle architecture in juvenile Alligator mississippiensis reveals an enhanced performance capacity of accessory breathing mechanisms. $J$ Anat 2021, 10.1111/joa.13523, doi:10.1111/joa.13523.

16. Cieri, R.L. The axial anatomy of monitor lizards (Varanidae). J Anat 2018, 233, 636-643, doi:10.1111/joa.12872.

17. Lyson, T.R.; Schachner, E.R.; Botha-Brink, J.; Scheyer, T.M.; Lambertz, M.; Bever, G.S.; Rubidge, B.S.; de Queiroz, K. Origin of the unique ventilatory apparatus of turtles. Nature Communications 2014, 5, 5211, doi:10.1038/ncomms6211.

18. O'Reilly, J.C.; Summers, A.P.; Ritter, D.A. The Evolution of the Functional Role of Trunk Muscles During Locomotion in Adult Amphibians1. American Zoologist 2015, 40, 123-135, doi:10.1093/icb/40.1.123.

19. Omura, A.; Anzai, W.; Endo, H. Functional and morphological variety in trunk muscles of Urodela. J Vet Med Sci 2014, 76, 159-167, doi:10.1292/jvms.13-0211.

20. Porro, L.B.; Richards, C.T. Digital dissection of the model organism Xenopus laevis using contrast-enhanced computed tomography. J Anat 2017, 231, 169-191, doi:10.1111/joa.12625.

21. Taylor, G.I.; Minabe, T. The angiosomes of the mammals and other vertebrates. Plast Reconstr Surg 1992, 89, 181-215, doi:10.1097/00006534-199202000-00001.

Callegari, P.R.; Taylor, G.I.; Caddy, C.M.; Minabe, T. An anatomic review of the delay phenomenon: I. Experimental studies. Plast Reconstr Surg 1992, 89, 397-407; discussion 417-398.

23. Rozen, W.M.; Ashton, M.W.; Taylor, G.I. Reviewing the vascular supply of the anterior abdominal wall: redefining anatomy for increasingly refined surgery. Clin Anat 2008, 21, 89-98, doi:10.1002/ca.20585.

24. Ecker, A.; Haslam, G. The anatomy of the frog; Clarendon Press: Oxford, 1889.

25. Millard, N.; Stephenson, T.A. THE VASCULAR ANATOMY OF XENOPUS LAEVIS (Daudin). Transactions of the Royal Society of South Africa 1940, 28, 387-439, doi:10.1080/00359194009520022. 
27 Ghetie V., C.S., Cotofan V., Hillebrand A. Anatomical Atlas of Domestic Birds; Academic Republic of Socialist Romania: 1976; Vol. 1 .

28 Khanna, D.R.; Yadav, P.R. Biology of Reptiles; Discovery Publishing House Pvt. Ltd.: 2004.

Wyneken, J. The Anatomy of Sea Turtles; U.S. Department of Commerce NOAA Technical Memorandum NMFS-SEFSC-470: 2001; pp 74-104.

30. O'Donoghue, C.H. The Blood Vascular System of the Tuatara, Sphenodon punctatus. Philosophical Transactions of the Royal Society of London Series B 1921, 210, 175.

31. Calice, I.; Kau, S.; Knecht, C.; Otero, P.E.; Larenza Menzies, M.P. Combined caudal retrocostal and lateral ultrasound-guided approach for transversus abdominis plane injection: A descriptive pilot study in pig cadavers. PLoS One 2021, 16, e0248131, doi:10.1371/journal.pone.0248131.

32. Kfoury, T.T.; Ben Rehouma, M.; Zetlaoui, P.J.; Benhamou, D.; Mazoit, J.X. Parietal Block Using Bupivacaine in the Rat: An Anatomical, Behavioral and Histological Study. J Pain Res 2020, 13, 17-24, doi:10.2147/jpr.S213820.

33. Rozen, W.M.; Tran, T.M.; Ashton, M.W.; Barrington, M.J.; Ivanusic, J.J.; Taylor, G.I. Refining the course of the thoracolumbar nerves: a new understanding of the innervation of the anterior abdominal wall. Clin Anat 2008, 21, 325-333, doi:10.1002/ca.20621.

34. Francis, E.T.B. The Anatomy of the Salamander. Oxford University, United Kingdom, 1934.

35. Wyneken, J. Reptilian Neurology: Anatomy and Function. Veterinary Clinics of North America: Exotic Animal Practice 2007, 10, 837-853, doi:https://doi.org/10.1016/j.cvex.2007.05.004.

36.

Ellis, H. Applied anatomy of abdominal incisions. $\mathrm{Br} J$ Hosp Med (Lond) 2007, 68, M22-23, doi:10.12968/hmed.2007.68.Sup2.22839.

37. Naldaiz-Gastesi, N.; Bahri, O.A.; López de Munain, A.; McCullagh, K.J.A.; Izeta, A. The panniculus carnosus muscle: an evolutionary enigma at the intersection of distinct research fields. J Anat 2018, 233, 275-288, doi:10.1111/joa.12840.

38. Ashdown, R.R.; Done, S.H. Color atlas of veterinary anatomy. Volume 2 The horse; Mosby London, 2012.

39. Langwokthy, O.R. The Panniculus Carnosus in Cat and Dog and its Genetical Relation to the Pectoral Musculature. Journal of Mammalogy 1924, 5, 49-63, doi:10.2307/1373485.

40. Hanafy, B.; Karkoura, A.; Enany, E.; Alsafy, M.; Elgendy, S. Applied Anatomy and Computed Tomography of the Abdominal Wall of the Dog. Alexandria Journal of Veterinary Sciences 2017, 52, 28, doi:10.5455/ajvs.252085.

41. Ashleô Montagu, M.F. Anthropological significance of the musculus pyramidalis and its variability in man. American Journal of Physical Anthropology 1939, 25, 435-490.

42. Jit, I.; Banga, N. Incidence of pyramidalis muscle in north Indian subjects. J Anat Soc India 1986, 35, $21-27$.

43. Natsis, K.; Piagkou, M.; Repousi, E.; Apostolidis, S.; Kotsiomitis, E.; Apostolou, K.; Skandalakis, P. Morphometric variability of pyramidalis muscle and its clinical significance. Surg Radiol Anat 2016, 38, 285-292, doi:10.1007/s00276-015-1550-4.

44. Didia, B.; Loveday, O.; Christian, I. Variation and incidence of agenesis of the pyramidalis muscles in Nigerian males. Journal of Experimental and Clinical Anatomy 2009, 8.

45. Das, S.S.; Saluja, S.; Vasudeva, N. Biometrics of Pyramidalis Muscle and its Clinical Importance. J Clin Diagn Res 2017, 11, Ac05-ac07, doi:10.7860/jcdr/2017/24179.9276.

46. Ashdown, R.R.; Done, S.H. Color atlas of veterinary anatomy - Volume 3: The Dog and Cat; Mosby/Elsevier: Edinburgh; Toronto, 2010; Vol. 3.

47. Evans, H.; Edward, d.L.; Alexander, M.; Malcolm, E. Miller's anatomy of the dog; Elsevier Saunders: St. Louis (Mo), 2013.

48. Olude, M.A.; Mustapha, O.A.; Ogunbunmi, T.K.; Olopade, J.O. The Vertebral Column, Ribs, and Sternum of the African Giant Rat (<i>Cricetomys gambianus $</ \mathrm{i}>$ Waterhouse). The Scientific World Journal 2013, 2013, 973537, doi:10.1155/2013/973537.

49. DeSesso, J.M.; Scialli, A.R. Bone development in laboratory mammals used in developmental toxicity studies. Birth Defects Res 2018, 110, 1157-1187, doi:10.1002/bdr2.1350. 
50. Matsuo, T. The Medio-Ventral Muscles of the Abdomen in Macacus cyclopsis (M. rectus abdominis and M. pyramidalis).

51. Brown, S.H.; Banuelos, K.; Ward, S.R.; Lieber, R.L. Architectural and morphological assessment of rat abdominal wall muscles: comparison for use as a human model. J Anat 2010, 217, 196-202, doi:10.1111/j.1469-7580.2010.01271.x. Lancaster, W.C.; Henson, O.W., Jr. Morphology of the abdominal wall in the bat, Pteronotus parnellii (Microchiroptera: Mormoopidae): implications for biosonar vocalization. J Morphol 1995, 223, 99-107, doi:10.1002/jmor.1052230109.

Arikawa, H. On the Latero-Ventral Muscles of the Abdomen of the Macacus cyclopsis. Okajimas Folia Anatomica Japonica 1960, 36, 51-77, doi:10.2535/ofaj1936.36.1_51.

54. Casal, D.; Pais, D.; Iria, I.; Videira, P.A.; Mota-Silva, E.; Alves, S.; Mascarenhas-Lemos, L.; Pen, C.; Vassilenko, V.; GoyriO'Neill, J. Blood Supply to the Integument of the Abdomen of the Rat: A Surgical Perspective. Plast Reconstr Surg Glob Open 2017, 5, e1454, doi:10.1097/gox.0000000000001454.

55. Pavletic, M.M. Anatomy and circulation of the canine skin. Microsurgery 1991, 12, 103-112, doi:10.1002/micr.1920120210.

56. Minqiang, X.; Jie, L.; Dali, M.; Lanhua, M. Transmidline abdominal skin flap model in pig: refinements and advancements. J Reconstr Microsurg 2012, 28, 111-118, doi:10.1055/s-0031-1289162.

Mei, J.; Yin, Z.; Zhang, J.; Lui, K.W.; Hu, S.; Peng, Z.; Chen, S.; Tang, M. A mini pig model for visualization of perforator flap by using angiography and MIMICS. Surg Radiol Anat 2010, 32, 477-484, doi:10.1007/s00276-009-0588-6.

58. Hallock, G.G.; Rice, D.C. Cranial epigastric perforator flap: a rat model of a true perforator flap. Ann Plast Surg 2003, 50, 393397, doi:10.1097/01.Sap.0000041485.73158.Cb.

59. Degner, D.A.; Lanz, O.I.; Walshaw, R. Myoperitoneal microvascular free flaps in dogs: an anatomical study and a clinical case report. Vet Surg 1996, 25, 463-470, doi:10.1111/j.1532-950x.1996.tb01444.x.

60. Kigata, T.; Horikawa, Y.; Shibata, H. Arterial branching pattern of the rabbit femoral artery. Anatomical Science International 2021, 96, 273-285, doi:10.1007/s12565-020-00589-1.

61. Ghoshal, N.G. The arteries of the pelvic limb of the cat (Felis domesticus). Zentralbl Veterinarmed A 1972, 19, 78-85, doi:10.1111/j.1439-0442.1972.tb00295.x.

62. Lhuaire, M.; Hivelin, M.; Hunsinger, V.; Derder, M.; Delmas, V.; Abrahams, P.; Sommacale, D.; Kianmanesh, R.; Lantieri, L.; Fontaine, C. Descriptive anatomy of the inferior epigastric, subscapular and internal thoracic vascular pedicles in three domestic mammals: A comparative study. Morphologie 2021, 105, 217-226, doi:10.1016/j.morpho.2020.10.002.

63. Haacke, N.; Unger, J.K.; Haidenhein, C.; Russ, M.; Hiebl, B.; Niehues, S.M. Pig specific vascular anatomy allows acute infrarenal aortic occlusion without hind limb ischemia and stepwise occlusion without clinical signs. Clin Hemorheol Microcirc 2011, 48, 173-185, doi:10.3233/ch-2011-1401.

64. Giessler, G.A.; Friedrich, P.F.; Shin, R.H.; Bishop, A.T. The superficial inferior epigastric artery fascia flap in the rabbit. Microsurgery 2007, 27, 560-564, doi:10.1002/micr.20413.

65. Bowen, C.V.; Leach, D.H.; Crosby, N.L.; Reynolds, R. Microvascular anastomoses. A comparative study of fibrinogen adhesive and interrupted suture techniques. Plast Reconstr Surg 1996, 97, 792-800, doi:10.1097/00006534-199604000-00016.

66. Balastegui, M.T.; Ramos-Plá, J.J.; Ferrer-Puchol, M.D.; Carrillo, J.M.; Monteagudo-Franco, S.P.; Esteban, E.; Liste, F. Anatomical variations in the aortic bifurcation in new zealand white rabbits on arteriography. Anat Rec (Hoboken) 2014, 297, 663-669, doi:10.1002/ar.22874.

67. Padubidri, A.N.; Browne, E., Jr. Modification in flap design of the epigastric artery flap in rats--a new experimental flap model. Ann Plast Surg 1997, 39, 500-504, doi:10.1097/00000637-199711000-00010.

68. Taylor, G.I.; Gianoutsos, M.P.; Morris, S.F. The neurovascular territories of the skin and muscles: anatomic study and clinical implications. Plast Reconstr Surg 1994, 94, 1-36, doi:10.1097/00006534-199407000-00001.

69. Hekmatpanah, J. Organization of tactile dermatomes, C1 through L4, in cat. J Neurophysiol 1961, 24, 129-140, doi:10.1152/jn.1961.24.2.129.

70. Kuhn, R.A. Organization of tactile dermatomes in cat and monkey. J Neurophysiol 1953, 16, 169-182, doi:10.1152/jn.1953.16.2.169. 
71. Bailey, C.S.; Kitchell, R.L.; Haghighi, S.S.; Johnson, R.D. Cutaneous innervation of the thorax and abdomen of the dog. Am J Vet Res 1984, 45, 1689-1698.

72. Castañeda-Herrera, F.E.; Buriticá-Gaviria, E.F.; Echeverry-Bonilla, D.F. Anatomical Evaluation of the Thoracolumbar Nerves Related to the Transversus Abdominis Plane Block Technique in the Dog. Anat Histol Embryol 2017, 46, 373-377, doi:10.1111/ahe.12279.

73. Portela, D.A.; Verdier, N.; Otero, P.E. Regional anesthetic techniques for the pelvic limb and abdominal wall in small animals: A review of the literature and technique description. Vet J 2018, 238, 27-40, doi:10.1016/j.tvj1.2018.07.003.

74. Hirigoyen, M.B.; Rhee, J.S.; Weisz, D.J.; Zhang, W.X.; Urken, M.L.; Weinberg, H. Reappraisal of the inferior epigastric flap: a new neurovascular flap model in the rat. Plast Reconstr Surg 1996, 98, 700-705, doi:10.1097/00006534-199609001-00016.

75. Singh, V.; Thrall, K.; Hauer-Jensen, M. Minipigs as models in drug discovery. Expert Opinion on Drug Discovery 2016, 11, doi:10.1080/17460441.2016.1223039.

76. Walters, E.M.; Prather, R.S. Advancing swine models for human health and diseases. Mo Med 2013, 110, $212-215$. 